\title{
Papers
}

Explorations into Children's Literature

\section{Boy Meets Music: Affective and Ideological Engagements in David Levithan's Boy Meets Boy, Love is the Higher Law, and Two Boys Kissing Rebecca Hutton}

Music is a source of both affective and social power. As 'a medium with a capacity for imparting shape and texture to being, feeling and doing' and a 'resource for social agency' (DeNora 2000, pp. 152-153), the experience of audible music can be particularly productive. To consider musical references as they appear in prose fiction, at first glance, seems to consider an engagement far removed from the cognitive and bodily experience of listening to music, and therefore its productive potential. Alisa Clapp-Itnyre (2002), however, employs a Bakhtinian approach to musical reference in fiction narrative when she theorises how music can function as part of the heteroglossia of the novel. As 'an equally vibrant language within the literary text', she argues, musical reference offers another site 'to engage social struggles' (pp. xviii - xix). Scholars have further argued that references to music in young adult fiction can enter into textual processes of ideological positioning, the construction of subjectivity, and the negotiation of adolescent identity at individual, social and political levels. ${ }^{1}$

This paper argues that references to music in three of David Levithan's young adult novelsBoy Meets Boy (2003), Love is the Higher Law (2009) and Two Boys Kissing (2013)—can be read as sites of affective and ideological engagement. The expectation of the reader's interaction with musical reference in these texts is sometimes subtle, but at other times overtly directed. In each instance, musical reference is a technique that invests readers in the social and political struggles in which each text aims to intervene. Boy meets Boy pairs popular jazz and disco songs of the 1960s and 1970s with diverse sexual identifications, and offers musical encounters as part of the text's overarching attempts at endorsing homosexual relationships. Love is the Higher Law, a narrative set in the immediate aftermath of 
September 11 2001, draws on connections with 1990s pop and rock music to prompt mobilisation of the young and the marginalised. And in Two Boys Kissing, music structures avenues for resistance and affirmation in which readers are directed to participate.

The way music appears and functions in each of these texts is also mediated by narrative style and genre. Love is the Higher Law is a realist narrative that models an idealised form of musical engagement for readers in relation to its ideological stance, while the didactic nature of Two Boys Kissing (a novel which is narrated by a chorus of the dead) intersects with the novel's tendency to instruct future generations in regards to ideological position and also in how best to adopt ways of reading music in fiction. Somewhat different once again, Boy Meets Boy sits in a space between magical realism, modern fairy tale, and speculative fiction. The text is constructed in a way that assumes readers will unquestioningly accept the existence of a town where hegemonies regarding sexuality and gender have been usurped. The shift in societal values, as the protagonist, Paul, narrates early in the text, was 'for the best' (Levithan 2003, p. 1) and he then goes on to demonstrate as much through the contrast of his hometown with that of his best friend, Tony. Music becomes part of a binary, as Paul's town is hyper-musicalised throughout the novel, whereas Tony's town, which remains homophobic and prejudiced, never features any music. As part of the musicalisation of Paul's hometown, the novel assumes readers will have the necessary understanding of a number of musical references, providing little to no detail apart from title and artist for many of the mostly popular or contemporary songs referenced.

Multiple references to music within a novel can create a soundtrack that is auxiliary, but also potentially significant, to the narrative and the text as a whole. T. A. Graham (2009) terms this a 'literary soundtrack', defined as 'a series of written references to specific pieces of music that compel extra-literary responses in readers and thereby heighten, color, or otherwise comment upon the text that contains them' (p. 519). There are similarities here with contemporary perspectives regarding affect, namely in regards to affect as situational intensities or resonances. Brian Massumi (2015) conceptualises affect as a 'virtual copresence of potentials’ (p. 24), while Gregory J. Seigworth and Melissa Gregg (2010) elaborate on affect as 'a momentary or sometimes more sustained state of relation [...] found in those intensities that pass body to body' (p. 1). Bodies in this context are not limited to living bodies, as these encounters can also involve non-human or material bodies, including such encounters as those between novel and reader or music and listener (see Gibbs 2010). 
The potential of such states of relation, or co-presences, first becomes evident in Boy Meets Boy. The novel is primarily marketed as a love story. It is across this love story that most of the convergences of musical reference and sexuality are initially apparent, intensifying engagements with the queer communities that exist within the text and offering a number of opportunities where readers may encounter resonances with the musical and extra-musical contexts of the songs that appear in the narrative. Protagonist Paul's first meeting with his love-interest, Noah, coincides with the first mention of music in the text, and other significant encounters between the two occur in conjunction with further musical accompaniment. They get to know each other to a backdrop of popular songs from the 1960s, 70s and 80s; they paint to the music of jazz singer Chet Baker; and their last appearance together in the narrative is linked to Louis Armstrong's 'What a Wonderful World'.

Boy Meets Boy is infused with multiple references to song titles and lyrics. Jes Battis (2011, p. 141) argues that the metaphorical use of song in the novel is part of what allows room for young readers to participate in the 'utopian process' the text attempts to initiate. This is particularly so in the final chapter when Paul draws on 'What a Wonderful World' to conclude his narration:

I see trees of green and dresses of white. I see Infinite Darlene whooping for joy as Amber attempts to dip her to the ground. I see Ted cheering them on as he strums an air guitar. I see Kyle and Tony talking quietly together, sharing their words. I see Joni leading Chuck in a slow dance. I see candles in the darkness and a bird against the sky. I see Noah walking over to me, care in his eyes, a blessed smile on his lips. And I think to myself, What a wonderful world. (Levithan 2003, p. 185)

The narrative adopts the song in a way that does not rely on, but still somewhat assumes, reader familiarity. As the first line of 'What a Wonderful World', and as one of the most iconic lines, the lyrical cue of 'I see trees of green' potentiates a moment whereby resonances or forces that pass between bodies potentially influence 'capacities' (Gibbs 2010, p. 188) for response. The words function as a cue for drawing on memory and experience for those familiar with the song. However, the shift to non-lyric half way through the sentence ('and 
dresses of white') merges contexts towards an ideological agenda. For example, in Amy Pattee's (2008) analysis of the final scene, the 'sentiment' of the novel is best communicated through 'What a Wonderful World', with the song reinforcing the 'naturalness' and 'utopian bliss' of a same-sex relationship (p. 159). The convergence of song and prose narrative in this instance bestows a strong utopic vision. Multiplicities of meaning are apparent in the titular line 'What a Wonderful World', which also becomes description (the scene that Paul sees before him), and in turn becomes a prophecy of a possible future. The evocation of 'bliss' that is a component of the text's challenge to heteronormativity is thus born of an interaction with the reference that, in turn, can contribute to readers' reception of the homosexual, bisexual, and transgender characters and their relationships noted in the scene. As such, the reference to the song itself reaffirms the 'naturalness' to which Pattee refers.

As Seigworth and Gregg (2010) suggest, 'it is quite likely that affect more often transpires within and across the subtlest of shuttling intensities: all the minuscule or molecular events of the unnoticed' (p. 2). To resonate with the often subtle or unnoticed musical references in a narrative is, to an extent, to experience an intensity and share an intimacy with the text that is not necessarily accessible to all readers. Nevertheless, the uncontextualised reference to the title/lyric/phrase 'What a wonderful world' speaks to an assumption of familiarity. Songs such as 'What a Wonderful World', Gloria Gaynor’s 'I Will Survive' and Queen’s 'We are the Champions’ appear in Boy Meets Boy with no contextualisation as to the genre, composition or lyrics of the songs. Yet they are included in ways that assume readers will understand the relevance of their placement in the narrative, such as why Paul's gay-straight alliance group chooses to play 'I Will Survive' after the Pledge of Allegiance every day. These expectations play into how the text operates, namely by asking readers to find or construct their own understanding in order to further participate in this aspect of the text's celebration of sexual diversity and critique of prejudice through song.

Musical reference in fiction exists as a nexus of meaning drawn from the context of the novel, the context of the song, and the reader. Such a confluence therefore means that transmission of meaning cannot be singular, stable, nor absolute. Graham (2009) argues that reader reception is critical to the way in which musical references in fiction produce meaning:

Just as the soundtracked novel puts two generically distinct arts into productive dialogue, so too does it represent a fluid, Barthesian complex of 
authorial intention and audience participation, a musicalized work of transmission or poesis that depends to an unusual extent on reception or esthesis. (p. 519)

As both 'a coded message’ and 'a process to be participated in' (Graham, p. 525), each musical reference creates a moment of semiotic absence in the narrative akin to Wolfgang Iser's (1978) 'gaps', where 'the hollow form of the text' needs to be 'filled [...] by the reader' (p. 225). Music that is referenced in prose fiction can therefore be considered in relation to intertextuality and the reader's (or interpreter's) participation in meaning-making. Andrzej Hejmej (2014), for example, chronicles how music in literature can be viewed through the lens of several structuralist and post-structuralist frameworks including Gerard Genette, Roland Barthes and Julie Kristeva’s conceptualisations of intertextuality. Throughout these and other frameworks, notions of reciprocity and productivity recur. Yet, while to some extent aligned with other, more traditional instances of intertextuality such as references to other literary works, fairy tale, or mythology, texts that refer to musical sources also break 'verbal borders’ (Hejmej, p. 28) and so are ‘inherently hybrid texts’ (p. 31).

The difficulty in attempting to interpret literary works that draw on musical intertexts without knowing, or knowing of, the sources can be difficult, in part because of this hybridity. ‘[M]usic brings with it a culturally constructed history of signs and signification', but also offers innumerable opportunities to destabilise those meanings (Taylor 2012, p. 218). The ephemerality of musical experience inevitably opens up spaces for multiple interpretations of meaning across listeners and, in turn, readers. This is particularly so when considering songs that were produced a decade or more before readers (and future readers) were born, as their encounters with, and understanding of, such songs may well be markedly different from those engaging with the song when it was first released.

Responses to, and understanding of, these references, however, are also in some ways facilitated by contemporary Western popular culture-including texts that also engage in intertextual relationships. The many contexts within which a single song might be presented across formats (i.e. radio, film, television, games) and the presentation within the narrative itself may direct audiences towards particular connections. For example, Gloria Gaynor’s disco hit 'I Will Survive', which appears in the second chapter of Boy Meets Boy, may evoke a number of associations that concurrently work towards delimiting its meaning. The song 
features in several texts released both before and after Boy Meets Boy was published, with a number of these pairing the song with non-hegemonic identity groups. For example, the song appears in the television show Glee (2009-2015) (as part of a mash-up with 'Survivor' by Destiny's Child); the iconic film The Adventures of Priscilla, Queen of the Desert (1994); the animated children's film Rio 2 (2014); reality shows such as The X Factor and versions of the Idol franchise; and even as part of karaoke and dance-themed games. Glee in particular aligns the song with sexuality through associating the performance and interwoven storyline with the characters of Santana and Brittany, who are lesbian and bisexual respectively, in the season three episode 'Hold on to Sixteen'. The song's status as a recognised 'gay anthem' (Kaminski and Taylor 2008, p. 58) also potentially intersects with mediated exposures to the lyrics and/or music that endorse associations with sexuality.

In Hejmej’s view, the 'literary score’ (a close relative of Graham’s literary soundtrack) is ‘a form of intersemiotic mimesis’ and thus ‘a cultural recontextualisation’ (2014, p. 30). This cultural recontextualisation is a key aspect of how Levithan's texts function. 'I Will Survive' is particularly powerful in its 'interplay of musical and verbal discourses of difference' (Hubbs 2007, p. 233), and the same can be argued of its usage in Boy Meets Boy. Nadine Hubbs (2007) identifies how disco songs_-and particularly Gaynor's song—can be considered 'a musical, social, and cultural space with [...] variously queer involvements' [original emphasis] (p. 232). In the song, a series of musical signifiers denote a shift from tragedy to transcendence to serve 'the identification needs of its audience in the margins, and even become[s] a vehicle for their rapture' (Hubbs, p. 236). In Boy Meets Boy, 'I Will Survive' is specifically paired with the Pledge of Allegiance, an association that implies the song holds the same level of significance for its 'audience in the margins' as the Pledge of Allegiance does for many Americans. The potential involvements and identifications Hubbs refers to, then, come into play in how the novel articulates and privileges gay experience. For example, Paul and the gay-straight alliance of his school play a portion of the song after the Pledge of Allegiance each day, an action which suggests a belief the song holds a form of power in terms of fostering understanding and community between groups.

'I Will Survive' also engages in a series of reversals that work towards a destabilisation of both musical and ideological hegemonies. There is a sustained use of a minor mode ${ }^{2}$ across the duration of the song, which would normally associate the song with sadness or melancholy. Minor can also be informally considered the 'other' mode when set against the 
‘conventionally normative’ major mode (Hubbs, p. 234). By using the minor mode consistently, but matching it with a change to an upbeat tempo and lyrics that evoke resonances with resilience and transcendence-growing strong, holding the head up high, being seen as somebody new, and the repetition of 'I Will Survive' - the song challenges the marginalisation and silencing of diverse sexual groups (Hubbs 2007). These reversals also mirror the work of the novel, whereby homosexual characters (who operate in a metaphorical 'minor mode’ in a number of texts) take precedence.

Levithan's 2009 anti-war novel Love is the Higher Law takes the convergence of music and sexuality further. Love is the Higher Law is more overtly political than Boy Meets Boy, situating engagement with music as an alternative response to the terrorist attacks of September 11, 2001 and the United States’ subsequent push for war. Set in New York, the narrative consists of three concurrent accounts of the minutes, hours, days, weeks, and months after the first plane hit the North Tower of New York’s World Trade Center. The young adult protagonists_-Peter, Jasper and Claire-narrate their individual chapters in present tense, lending an immediacy to their navigation of the aftermath despite the eightyear gap between event and publication. The three characters cope with the attack in different ways. Peter and Jasper's burgeoning romantic relationship is repeatedly interrupted by the immediate and longer-term trauma of the event, with Peter turning to music and Jasper becoming apathetic. Claire, alternatively, turns to establishing new or stronger ties with family and friends. Claire's narration begins and concludes the narrative, affording her a greater authority within the text than her two gay co-narrators. Yet it is actually Peter who seems best equipped in the post-September 11 world. Where Claire and Jasper both experience a hyper sense of disenfranchisement from the loss, Peter finds solace in his ties to music. These ties facilitate rebuilding his sense of community and belonging; he feels 'an energy [he doesn't] fully understand, something that's been missing these past few days and weeks' (Levithan 2009, p. 86) at a Travis concert and understands it as 'the energy of gathering' (p. 87, original emphasis). Importantly, Peter models how to participate in the energies of music, a demonstration that also gestures towards the social and affective power of music within and beyond the narrative.

Immediately after September 11, contemporary Western popular music 'changed dramatically as it adjusted to [a] new political reality' to be used 'in the service of mourning, healing, patriotism, and nation building' (Garofalo 2012, p. 4). Literature for children and 
young adults likewise encountered a shift as a number of bibliotherapeutic fictions addressing the event were swiftly produced for young readers (Bradford 2005) and 'new discourses about what it means to be a good and responsible citizen and about the nature of national identity’ emerged (Lampert 2010, p. 2). Published eight years after the events of September 11 and six years after the start of the war that the novel seeks to condemn, Love is the Higher Law does not fit easily into the category of bibliotherapy. Instead, the narrative is somewhat of a revisionist discourse, working from hindsight rather than as an immediate intervention to mediate the trauma of September 11. But the text still embodies a significant aspect of the bibliotherapeutic text, namely that the events 'are shaped to produce an ending where characters are seen to progress towards a “better” or “healthier” way of being’ (Bradford, p. 21).

This better or healthier way, according to the narrative, is achieved through music, which acts as a panacea for large-scale trauma and political unrest, and as a tool for negotiating individual subjectivity and sexuality. Music creates an 'arena', according to Aaron Lecklider (2006), 'where marginalised voices can be heard’ (p. 117). Jodie Taylor (2012) emphasises that music is '[m]uch more than a static object or product' (p. 49). Instead, she argues, 'music is a collection of interconnected activities and texts employed as strategic resources in the production and transmission of self-narrative and collective belonging' (p. 42). The novel addresses this social power of music when Peter describes his experience during the Travis concert:

We all realize that this gathering is about much more than the music, and what we're getting from it is much more than sounds. 'I want to live in a word where I belong', Fran Healy sings in 'Turn'. Then, later on, 'I want to live in a world where I'll be strong' Before when I listened to this, I would think about being gay, or about needing to be there for my friends, or even about more general things like being the main character in my own life. But now I realize it's even more general than that-it's about life itself. Fran promises it won't be very long, and we sing with him. Because we want to believe it. We want to believe the world will turn. We want to believe we'll survive. (Levithan 2009, p. 88) 
In this instance, the narrative aligns 'Turn' with Peter's affirmative experience of engagement and shared experience at the concert (the first he has attended since September 11). This scene is reminiscent of Bennet Reimer's conceptualisation of the experience of music, where the experience, itself, is created through the listener's 'self-generated affect as they share the expressive possibilities made tangible by the composer and performer' (Reimer and Wright 1992, p. 157). Love is the Higher Law enacts this idea, for character and reader, as it negotiates both trauma and the formation of subjectivity for the young person in the nexus of event and response.

As mentioned earlier, Boy Meets Boy tends to assume readers will understand the relevance of engagements with musical references in relation to the politics of the novel. Love is the Higher Law, in contrast, operates differently. The excerpt reproduced above involves a series of explanations elucidating how the music referenced is to be primarily read in relation to the narrative, the characters, and real world politics. Peter models the way music-based meaningmaking can be integrated into personal and political experiences when he lists his multitude of associations with the Travis song 'Turn'. Prior to the September 11 attacks, this included sexuality, localised community, subjectivity, and agency; post-September 11 this comes to include (rather than be replaced by) survival, existence in a global community, and hope for the future.

The narrative recites two particular lyrics from 'Turn': 'I want to live in a word where I belong' and 'I want to live in a world where I'll be strong', specifically pairing the desire for belonging and strength with both homosexuality and the aftermath of terrorism. The narrative presents music as a tool for articulating what is lacking and for potentially remedying this lack. The song reference contributes to the representation of Peter's disconnection, powerlessness, and marginalisation, first at an undisclosed point in his life because of his sexuality, and more recently in the aftermath of September 11. But it is also presented as part of an event (the concert) that has reparative effects for Peter. Further to this, 'Turn' (coincidentally or not) includes the lyric 'I will survive', meaning that both Love is the Higher Law and Boy Meets Boy share similarities in the thematic messages of survival and transcendence conveyed through both song choices.

Anna Gibbs (2013) suggests that we live in a 'continuous state of mediatized emergency and traumatic aftermath' that often leads to desensitisation or 'traumatic numbing' through 
overwhelming exposure to traumatic stimuli such as repeated imagery (p. 130). The musicnarrative interaction in Love is the Higher Law works towards circumventing this numbing; not to reignite the original trauma state itself, but as a tool of enabling resonances and ideological transfer with readers who are now somewhat temporally removed from September 11. This is particularly so in the reference to U2's 'One' that appears in Peter's third last chapter. The title of Levithan's novel is taken from the lyrics of 'One', with the phrase biblical in its allusion to a 'love thy neighbour' sentiment (Lampert, 2014, p. 259). U2's music is densely populated with Christian themes and iconography (see Fast 2000) and Levithan's novels likewise often enter into dialogues between religion and sexuality (see Battis 2011). The song itself has been read in terms of a multitude of meanings by scholars, critics, and fans alike, including conflict in romantic or familial relationships, a response to German reunification, or a narrative of dying from HIV/AIDS to name a few. The use of 'One' in Love is the Higher Law means this multiplicity of meaning can oscillate between both the personal and political significances of the text.

'One' appears in Love is the Higher Law when Peter attends a U2 concert, a historical event that occurred in New York City on October 27, 2001. Again, the expression of the musicalised encounter is conveyed within Peter's narration:

Then the band gets to 'One'.' As Bono sings, the names of all of the 9/11 victims are projected onto the backdrop of the stage. All of those names. And the song transforms into something much bigger than it is. And we transform into something much bigger than we are. We are crying and holding on to each other and singing along and reading, reading, reading. (2009, p. 122)

The projection of the names during the performance of the song happened at the real-world concert. Levithan's usage of the song and the concert situates it as part of the patriotism of the novel which, interestingly, tends to be limited to the city, rather than the country as a whole. As part of this limited patriotism, the narrative resists a concurrent aspect of the show. During 'Walk On', the band brought a large group of New York firefighters onto the stage. The firefighters, wearing their uniforms and waving American flags, were led by a marching Bono onto a circular platform that extended into the cheering crowd then back onto the stage. After the song, a handful of firefighters then spoke as audience members cheered and chanted 
'USA' in a highly emotive—but also highly politicised—show of unity and patriotism.

By exorcising these aspects from the narrative, the text foregrounds the reparative effects of the music for victims of trauma rather than the valorisation of heroism that would come to be part of the propaganda of the War on Terror. Likewise, in focalising this experience through Peter, the experience is aligned with (and thus also offered to) those of non-hegemonic sexual identifications and the wider young adult population. Earlier in the chapter, Peter contemplates U2's catalogue and refers to 'Walk On' as a song for 'moving' (p. 120), but rather than the mobilisation of government forces, the song is instead re-signified as embodying the mobilisation of the young and marginalised. This is particularly pertinent when, early in the novel, Jasper's sense of helplessness in the face of the attack and aftermath is heightened by being restricted from being able to donate blood because he has had sex with men (pp. 30-31). Where Peter's experience strengthens his links to others, Jasper's experience reinforces his marginalised status. For the young reader, reading many years after the event, the call to mobilisation may no longer exist entirely in relation to September 11 itself. Instead, through the convergence of references to music and the experiences of homosexual characters after a landmark cultural trauma, the narrative also models and prompts a more universalised call to response and action on open-ended political and personal fronts.

Lawrence Grossberg (1992) argues that affective engagement between bodies 'produces maps which direct our investments; these maps tell us where and how we can become absorbed — not into the self but into the world—as potential locations for our selfidentifications, and with what intensities' (p. 57). It is in Two Boys Kissing (2013), published ten years after Boy Meets Boy and the most overtly didactic of the three texts discussed here, that the significance of the resonances available through musical reference in Levithan's works is articulated most clearly. The novel is narrated by a chorus of those who died of HIV/AIDS, a universalised 'we' who watch over the current generation of gay and transgender youth. Their focus is a handful of teenagers: Peter, Neil, Ryan, Avery, Harry, Craig, Tariq, and Cooper. As they watch over Tariq in the first chapter, they reflect on his connection to music, and by extension their own:

Music isn't much different now from what it was when we hit the dance floor. This means something. We found something universal. 
We bottled that desire, then released it into the airwaves. The sound hits your body, and you move. We are in those particles that send you. We are in that music. (Levithan 2013, p. 4)

The chorus remains unheard by the characters in the novel, and is unable to affect anything in their narrative world. Yet the chorus is primarily responsible for the communication of the characters' experiences and feelings, as well as for linking past to present to future. These ephemeral figures are an embodiment of a force akin to affect, as they themselves are resonances born of 'memory [and] experience' (Gibbs 2010, p. 187) within and beyond the narrative.

Musical reference in the text structures avenues of both resistance and affirmation. The greatest act of resistance-Harry and Craig's lengthy kiss, undertaken to break the Guinness World Record for longest kiss, but also as a response to prejudice and violence-is soundtracked. Music plays around them for the 'thirty-two hours, twelve minutes, and ten seconds' needed to break the record (p. 42). Music also factors into further defiance in the face of overt homophobia. When protestors shout abuse at the boys, the response is to turn the music up louder and to play a Lady Gaga mashup of 'Express Yourself' and 'Born This Way'. Tariq's relationship with music is also considered on a more personal level in relation to the song. Tariq, a victim of homophobic violence months earlier, uses 'Born This Way/Express Yourself' to 'take him away from what just happened' (p.112). The song also in part comes to define ‘their space, their domain' (just as songs like 'I Will Survive' have in earlier Levithan texts), with 'their' primarily referring to the group of homosexual and transgender characters at the heart of the scene, and the novel as a whole.

The use of 'Born This Way' is particularly pertinent in regards to both the personal and political contexts of homosexuality in the narrative. Jang and Lee (2014) suggest that the song plays a role in influencing attitudes towards homosexuality and gay rights and that its lyrics prime individuals to consider gay rights more favourably through the lens of genetic explanations of homosexuality. The song was released in 2011, relatively close to the publication of the novel in 2013, meaning the immediate readership may have a higher chance of being familiar with the song. ' 'I Will Survive' (1978) and 'What a Wonderful World’ (1967), alternatively, were released at least 25 years before Boy Meets Boy’s publication, and even ‘Turn’ (1999) and ‘One’ (1991) had a gap of four to twelve years 
between release and their appearance in Love is the Higher Law. The relative contemporaneity of 'Born This Way' also potentially aids in how the song might address post-millennium queer youth in ways that a song such as Gaynor's may not be able to to shifts in the zeitgeist, such as disco falling out of favour to instead become a more nostalgic or ironic experience for listeners.

Like Gaynor’s ‘I Will Survive’, 'Born This Way’ has entered the cultural corpus as an ‘international gay anthem’ (Jang and Lee 2014, p. 118). Lady Gaga’s popular hit, however, expects and encourages clear associations with diverse gender and sexual identifications somewhat differently to Gaynor's song, which was adopted by, more than consciously directed towards, queer communities. For example, immediately after its release, reviewers and critics unequivocally termed 'Born This Way' a gay anthem, the lyrics refer to GLBTQI communities, the title intersects with genetic explanations of homosexuality, and a rainbow appears at the end of the video clip for the song. Such discourses and allusions thus potentially delimit listener reception of the song and also potentially influence subsequent associations in other contexts such as literature.

All three texts discussed in this article draw on the affective atmospheres of musical references in their construction and, in each instance, these references call upon the reader to some extent. Yet it is in Two Boys Kissing that this call is most unequivocally articulated. In narrating the emerging relationship between Ryan, a blue-haired gay boy, and Avery, a pinkhaired transgender boy, the chorus turns to Aretha Franklin's 'What a Diff'rence a Day Made' to imbue the scene with a resonance that the chorus believes can only be expressed through music. No one can "articulate it in the same way Aretha does, when she bursts out with 'It's heaven, heaven, heaven when you/When you find love and romance on the menu'”, they explain, before issuing a directive not to the characters, but to the readers: 'Go and listen to it right now-you have it right at your fingertips, for less than the price of a candybar' (p. 121). A direct address like this to the reader underscores the text's didacticism, particularly in its reversal of the treatment of musical reference as compared to Levithan's other two texts. The assumption here is instead that readers do not have the prior understanding of the song necessary to adequately make meaning from the reference. Two Boys Kissing, then, 'teaches' readers how to enhance their understanding of the song; it enables the reference to better engage readers with the politics of the narrative. There is no better way to articulate (and celebrate) the relationship between two boys, according to the novel, than by drawing on 
affects created through pairing the prose narrative with real world musical experience.

Boy Meets Boy, Love is the Higher Law and Two Boys Kissing thus present three musicalised versions of the world against which readers can measure their own world. Be it Boy Meets Boy's 'wonderful' world set to a soundtrack of transcendence and bliss, Love is the Higher Law's unified gatherings of healing and belonging against a backdrop of live music, or Two Boys Kissing's structuring of affirmative spaces through song, each text's references to music offer opportunities for resonances and investments that potentially 'incite [...] bodies into [...] response' (Gibbs 2010, p. 192). These texts demonstrate how music can hold both affective and social power across multiple contexts, from audible experience to written references. The myriad affective and ideological engagements made available through musical references in these novels may not be fixed or entirely predictable. However, each reference that appears in the narrative creates gaps that young readers are encouraged to fill and to, in effect, find ways to 'sing along' .

\section{Acknowledgements}

The author would like to thank the many scholars who provided valuable feedback for partial or full drafts of this paper, including Cassandra Atherton, Clare Bradford, the anonymous reviewers, and the editors. Thanks also to Elizabeth Braithwaite for her generous assistance in negotiating the nuances of major and minor modes.

\section{Notes}

${ }^{1}$ See Nodelman 1992; Battis 2011; Coats 2012; Braithwaite 2014. For more regarding the relationship between adolescent development and music, see in particular Coats 2012.

${ }^{2}$ In music, mode often influences the perceived emotion of a piece of music (Trochidis and Bigand 2013, p. 142). Mode is constituted by the way pitch intervals are organised, with minor modes characterised as having three semitones between the tonic note and the third of the scale. In Western music, the minor modes are often, though not always, perceived to convey seriousness, sadness or tragedy (see, for example, Trochidis and Bigand 2013). According to Hubbs, '[t]he minor frequently arises in slow-tempo tender or tragic love ballads’ while ‘up-tempo danceable [...] anthems are typically in major’ (p. 234), though there are exceptions to this. See Hubbs for more, including further musicological analysis of 'I Will Survive'. 
3 The song was extremely popular and broke several chart and sales records (see, for example, Trust 2011).

\section{References}

Battis, Jes (2011). 'Almost Paradise: Queer Utopias in Abeyance in David Levithan's Wide Awake and Boy Meets Boy'. In Annette Wannamaker (ed.) Mediated Boyhoods: Boys, Teens, and Young Men in Popular Media and Culture. New York: Peter Lang, pp. 135-144.

Bradford, Clare (2005). ‘Children’s Literature in the “Age of Terrorism”: Subtexts in Literary Responses to September 11, 2001'. Magpies 20 (1): 20-23.

Braithwaite, Elizabeth (2014). 'The Site of "Becoming”: Music and Adolescence as Liminal Spaces in a Selection of Young Adult Fictions'. Interjuli 1: 27-46.

Clapp-Itnyre, Alisa (2002). Angelic Airs, Subversive Songs: Music as Social Discourse in the Victorian Novel, Athens: Ohio University Press.

Coats, Karen (2012). ““The beat of your heart”: Music in Young Adult Literature and Culture'. In Mary Hilton and Maria Nikolajeva (eds) Contemporary Adolescent Literature and Culture: The Emergent Adult. Burlington: Ashgate, pp. 111-125.

DeNora, Tia (2000). Music in Everyday Life, Cambridge: Cambridge University Press.

Fast, Susan (2000). 'Music, Contexts and Meaning in U2'. In Walter Everett (ed.) Expression in Pop-Rock Music: A Collection of Critical and Analytical Essays. New York: Garland, pp. 33-57.

Garofalo, Reebee (2012). 'Pop Goes to War, 2001-2004: US Popular Music after 9/11'. In Jonathan Ritter and J. Martin Daughtry (eds) Music in the Post-9/11 World. New York: Routledge, pp. 3-26.

Gibbs, Anna (2010). ‘After Affect: Sympathy, Synchrony, and Mimetic Communication’. In Melissa Gregg and Gregory J. Seigworth (eds) The Affect Theory Reader. Durham: Duke University Press, pp. 186-205.

---. (2013). 'Apparently Unrelated: Affective Resonance, Concatenation and Traumatic Circuitry in the Terrain of the Everyday'. In Meera Atkinson and Michael Richardson (eds) Traumatic Affect. Newcastle Upon Tyne: Cambridge Scholars Publishing, pp. 129-147.

Graham, T. Austin (2009). 'The Literary Soundtrack: or, F Scott Fitzgerald's Heard and Unheard Melodies’. American Literary History 21 (3): 518-29.

Grossberg, Lawrence (1992). 'Is There a Fan in the House?: The Affective Sensibility of Fandom'. In Lisa A. Lewis (ed.) Adoring Audience: Fan Culture and Popular Media. New York: Routledge, pp. 50-65. 
Hejmej, Andrzej (2014). Music in Literature: Perspectives of Interdisciplinary Comparative Literature, trans. Lindsay Davidson. Frankfurt am Main: Peter Lang.

Hubbs, Nadine (2007). “"I Will Survive”: Musical Mappings of Queer Social Space in a Disco Anthem’. Popular Music 26 (2): 231-244.

Iser, Wolfgang (1978). The Act of Reading: A Theory of Aesthetic Response. Baltimore: Johns Hopkins University Press.

Jang, S. Mo and Hoon Lee (2014). 'When Pop Music Meets a Political Issue: Examining how “Born this Way” Influences Attitudes Towards Gays and Gay Rights Policies'. Journal of Broadcasting and Electronic Media 58 (1): 114-130.

Kaminski, Elizabeth and Verta Taylor (2008). “"We're not just lip-synching up here”: Music and Collective Identity in Drag Performances’. In Jo Reger, Daniel J. Myers, and Rachel L. Einwohner (eds) Identity Work in Social Movements. Minneapolis: University of Minnesota Press, pp. 47-76.

Lampert, Jo (2010). Children's Fiction About 9/11: Ethnic, National and Heroic Identities. New York: Routledge.

---. (2014). 'Self in the City: Young Adult Fiction about New York City after 9/11'. In Padraic Whyte and Keith O’Sullivan (eds) Children's Literature and New York City. New York: Routledge, pp. 243-264.

Lecklider, Aaron (2006). 'Introduction’. Journal of Popular Music Studies 18 (2): 117-123.

Levithan, David (2003). Boy Meets Boy. New York: Alfred A. Knopf.

---. (2009). Love is the Higher Law. New York: Alfred A. Knopf.

---. (2013). Two Boys Kissing. New York: Alfred A. Knopf.

Massumi, Brian (2015). 'Navigating Movements: Interview with Mary Zournazi'. Politics of Affect. Cambridge: Polity, pp. 1-46.

Nodelman, Perry (1992). 'Males Performing in a Female Space: Music and Gender in Young Adult Novels'. The Lion and the Unicorn 16 (2): 223-239.

Pattee, Amy S. (2008). 'Sexual Fantasy: The Queer Utopia of David Levithan's Boy Meets Boy’. Children’s Literature Association Quarterly 33 (2): 156-171.

Reimer, Bennett and Jeffrey E. Wright (1992). On the Nature of Musical Experience. Niwot: University Press of Colorado.

Seigworth, Gregory J. and Gregg, Melissa (2010) ‘An Inventory of Shimmers’. In Melissa Gregg and Gregory J. Seigworth (eds) The Affect Theory Reader. Durham: Duke University Press, pp. 1-25.

Taylor, Jodie (2012). Playing it Queer: Popular Music, Identity and Queer World-Making. Bern: Peter Lang. 
Trochidis, Konstantinos and Emmanuel Bigand (2013). 'Investigation of the Effect of Mode and Tempo on Emotional Responses to Music using EEG Power Asymmetry’. Journal of Psychophysiology 27 (3): 142-147.

Trust, Gary (2011, February 16). 'Lady Gaga Claims 1,000 ${ }^{\text {th }}$ Hot 100 no. 1 with "Born this Way”’. Billboard. Retrieved from http://www.billboard.com

\section{Biographical Note}

Rebecca Hutton is a $\mathrm{PhD}$ candidate in the School of Communication and Creative Arts at Deakin University, Melbourne. She has previously co-authored a chapter on Arthurian children's television (Bradford and Hutton, 2015) and an article on young adult post-disaster fiction (Braithwaite, Hutton and Miller, 2012). This paper is drawn from her PhD research on the intersections between music and sexuality in young adult fiction. 